\title{
Splenic and Leucocytic Responses in Wistar Rats Exposed to Chronic Doses of Hydromethanol Extract of Helianthus Annuus Leaf in Feed
}

\author{
Gladys Chinelo Ezeh ${ }^{1}$, Samuel Okwudili Onoja ${ }^{2 *}$, Maxwell Ikechukwu Ezeja ${ }^{2}$, \\ Samuel Chukwunyere Udem ${ }^{3}$, Aruh Otta Anaga $^{3}$ \\ ${ }^{1}$ Department of Agriculture, Alex Ekwueme Federal University Ndufu Alike-Ikwo, Ebonyi State, Nigeria. \\ ${ }^{2}$ Department of Veterinary Physiology and Pharmacology, Michael Okpara University of Agriculture \\ Umudike, Abia State, Nigeria. \\ ${ }^{3}$ Department of Veterinary Physiology and Pharmacology, University of Nigeria, Nsukka, Enugu State, \\ Nigeria.
}

\begin{abstract}
To evaluate the effects of the hydromethanol extract of Helianthus annuus on leucocyte profile and spleen histology after prolonged exposure to Wistar rats. This study involved the incorporation of varied concentrations $(2.50,5.00$ and $10.00 \mathrm{mg} / 10 \mathrm{~g}$ ) of hydromethanol extract of $H$. annuus in feed and feeding same to Wistar rats for 90 consecutive days. Blood samples were collected from the retro-orbital plexus of the rats on days 30,60 and 90 , for leucocyte count. Histopathological examination of the spleen was also conducted. The extract treatment did not cause a significant $(p>0.05)$ change in the leucocyte profile and the spleen histology in the treated rats when compared to the normal control rats. On day 90, the total leucocyte counts of $15.24 \pm 1.47,12.69 \pm 0.84$ and $16.29 \pm 3.36$ for the groups that were treated with extract $2.50,5.00$ and $10.00 \mathrm{mg} / 10 \mathrm{~g}$ feed respectively, were not significantly $(p>0.05)$ different when compared with the total leucocyte count $(12.01 \pm 0.77)$ of the control group. The findings suggest that hydromethanol extract of $\mathrm{H}$. annuus do not have a significant effect on the leucocyte profile and the histology of spleen.
\end{abstract}

Keywords: leucocyte profile, spleen histology, chronic toxicity, herbal medicine, Helianthus annuus

\section{Introduction}

The use of herbal products to treat both human and animal diseases has been handed down from one generation to another from time immemorial. In recent times, the use of herbal products is gaining more acceptance [1]. The World Health Organization (WHO) estimated that about $80 \%$ of the populace in both developed and developing nations use herbal medicine in one way or other in their health care needs [1, 2]. The estimated percentage of the population that have used herbal products at least once for health care in

\footnotetext{
* Corresponding author Samuel Okwudili Onoja, onoja.samuel@mouau.edu.ng

(cc) EY-NC-ND 2021 G.C. Ezeh et al.,published by De Gruyter Open. This work was licensed under the Creative Commons Attribution-NonCommercialNoDerivs 3.0 License
}

developed nations such as Canada, France, Australia, USA and Belgium are $70 \%, 49 \%, 48 \%$, $42 \%$ and $31 \%$, respectively $[3,4]$. The percentage are higher in the developing and underdeveloped nations due to the poor state of their health care system [5]. The factors that aid in the increasing interest in herbal medicine are; economic crunch, high cost, decline in efficacy due development of resistance, unavailability and side effects of orthodox medicine [6]. Herbal products on the other hand are increasingly utilized due to its ease of access, affordability, efficacy, reduced side effects and cultural acceptance because of its closeness to nature [7].

Despite the increasing use of herbal products in disease management, the practice is being criticized on the ground that it lacks scientific assessment of their toxicity, while some herbal 
preparations have been found to be toxic and/or contain toxic phytoconstituents [8]. The WHO has recommended the safety evaluation herbal products for effective regulation and monitoring. As a result, there is a need to evaluate the toxicity profile of herbal products in various organ systems $[9,10]$. One of the organ system readily affected by toxicants is hematological system. Leucocytic response and changes in spleen histology are usually expressed when hazardous chemicals or toxic herbs that induce stress are ingested [11-14]. One of the commonly used herbal medicine is Helianthus annuus leaf.

Helianthus annuus Linn commonly known as sunflower, belongs to the family Asteraceae. It has a universal distribution. In folkloric medicine, the decoctions, poultice and infusions are used in oedema, high blood glucose, respiratory, gastrointestinal, microbial infection, snakebite and pain management [6]. Some pharmacological properties of the leaves such as analgesic, antiinflammatory, antidiabetic, antioxidant, antidiarrheal, antihistaminic, antilithiatic and antimicrobial activities have been reported [15]. Toxicological properties such as antifertility, antispermatogenic and anaemic activities of $H$. annuus have been documented [16]. Previous chronic studies have reported that prolonged administration of $H$. annuus for about 90 days caused degenerative changes in the kidney, liver and testicles, and also mild normocytic hypochromic anemia [6,15]. There is a dearth of information on the effects of $H$. annuus on the leucocyte and spleen. Hence, this study was designed to evaluate the effects of the hydromethanol extract of $H$. annuus on leucocyte profile and spleen histology after prolonged exposure to rats.

\section{Material and Methods}

Plant Collection and Extract Preparation

Helianthus annuus leaves were harvested from the wild in Nsukka, Enugu State, Nigeria and identified by plant taxonomist. The leaves were dried on laboratory bench at environmental temperature $\left(25-27^{\circ} \mathrm{C}\right)$. Hydromethanol extract of $H$. annuus leaf was prepared using cold maceration method as described by Onoja and Anaga [17] and was referred to as hydromethanol extract of $H$. annuus leaf (HLEHA).

\section{Experimental Animals}

Fifty six (56) mature female albino Wistar rats (80 $-90 \mathrm{~g}$ ) obtained from the research animal colony of the Department of Veterinary Physiology and Pharmacology, Michael Okpara University of Agriculture Umudike, were used for the study. They were kept in aluminum cages in a well- ventilated room at environmental temperature $(25$ $-27^{\circ} \mathrm{C}$ ) and 12 hours light/darkness cycle. The rats were allowed to acclimatize for two weeks and the ethical approval for this study was obtained from the College of Veterinary Medicine, Michael Okpara University of Agriculture, Umudike Research Ethics Committee (MOUAU/CVM/REC/201911). The animals were managed as prescribed in the Guide for the Care and Use of Laboratory Animals of National Research Council.

\section{Feed Formulation}

Graded levels of HLEHA (2.5, 5 and $10 \mathrm{mg} / 10 \mathrm{~g}$ ) was incorporated in the standard poultry feed as described by Onoja et al. [15].

\section{Experimental Design}

The rats were randomly assigned to $4(A-D)$ groups of 14 rats each and treated as follows: group A rats received standard pelleted feed while rats in groups $B-D$ received feed incorporated with HLEHA at $2.5,5$ and $10 \mathrm{mg} / 10 \mathrm{~g}$ feed, respectively. They were fed $10 \%$ of their body weight daily for 90 consecutive days. They finished their feed each day and a deep feeding troughs were used to avoid feed wastage. On weekly basis, the rats were weighed and their feeding adjusted to accommodate the weight change. The hematological profiles of the rats were determined on day 30, 60 and 90 of treatment. Four animals were randomly selected from each group at the timed interval and blood samples were collected from the retroorbital venous plexus with the aid of heparinized capillary tube into ethylenediaminetetraacetic acid (EDTA) bottle. The parameters were determined within 24 $\mathrm{h}$ of blood sample collection. Thereafter, the rats were humanely sacrificed, the spleen was excised and stored in $10 \%$ formal saline.

\section{Total leucocytic profile}

The total white blood cell (WBC) count was determined by using hemocytometer method. The blood sample was diluted (1:20) using Turks solution ( $2 \%$ glacial acetic acid). The diluted blood sample was loaded into a Neubauer counting chamber with the aid of a Pasteur pipette. The WBC was determined by counting the required number in the appropriate squares on the counting chamber under a microscope. The number of cells counted for each blood sample was multiplied by 50 to obtain the total white blood cell count per microlitre of blood [18]. Manual methods of hematological analysis were adopted instead of automated method because the available automated hemoanalyzer was programmed for human sample and do not give 
detailed, accurate and reliable leucocyte profile of rodent sample.

\section{Differential leucocyte count}

Thin blood smear was made on clean dry and grease free microscope slide from each of the collected blood sample in EDTA. The slides were air dried and stained with Giemsa stain as described in Brar et al. [18]. The slides were later examined with light microscope under oil immersion. The relative number of the neutrophil, lymphocyte, eosinophil, basophils and monocytes were estimated. The absolute numbers of the above cell types were calculated from the total WBC count.

$$
\text { Absolute number }\left(\times 10^{3} / \mu \mathrm{L}\right)={ }^{(\text {Relative number } \times \text { total } \mathrm{WBC})} / 100
$$

\section{Histopathology}

The spleen tissue sections were processed and stained with hematoxylin and eosin dye as described by Ezeja et al. [19]. Photomicrographs of the sections were captured at 400x magnifications with an Olympus photomicroscope (Olympus Scientific Equipment, Ashburn, VA).

\section{Data Analysis}

The data were presented as mean \pm standard error of mean (SEM), analyzed using one-way analysis of variance (ANOVA). The variant mean were separated by least significant difference (LSD) tests using SPSS statistical software version 21.0. Values of $p<0.05$ were considered significant.

\section{Results and Discussion}

There was no significant $(p>0.05)$ difference in the WBC count of the various groups on day 30 , 60 and 90 (Table 1). There was no significant $(p>$ 0.05 ) difference in the absolute neutrophil count (Table 1) of the various groups on day 30,60 and 90 , but there was time dependent decrease in the relative and absolute neutrophil count of all the groups. There was no significant $(p>0.05)$ change in the absolute lymphocyte count (Table 1) of the extract treated groups when compared with the control group. On day 30 , the absolute eosinophil count (Table 1) of group D was significantly $(p<0.05)$ increased when compared to control group while on day 60 , absolute eosinophil count of groups $C$ and $D$ were significantly $(p<0.05)$ decreased when compared to control group. On day 90, there was no significant $(p>0.05)$ difference on the eosinophil count of all the groups. On day 30 , the absolute monocyte count (Table 1) of groups $C$ and $D$ are decreased ( $p<0.05$ ) when compared to control while there was no difference $(p>0.05)$ in the monocyte count of the treated groups when compared to control. On day 60 , the absolute basophil count (Table 1) of group $B$ and $D$ were significantly $(p<0.05)$ decreased when compared to control group. The photomicrograph sections of spleen tissues showed no pathological changes; thus the architecture was normal (Figure 1).

Effects of HLEHA on absolute leucocyte count in normal rats

\begin{tabular}{|c|c|c|c|c|c|}
\hline \multirow{2}{*}{$\begin{array}{l}\text { Parameters } \\
\left(\times 10^{3} / \mu L\right)\end{array}$} & \multirow[t]{2}{*}{ Days } & \multirow[t]{2}{*}{ CONTROL } & \multicolumn{3}{|c|}{ HLEHA (mg/10 g feed) } \\
\hline & & & 2.50 & 5.00 & 10.00 \\
\hline \multirow{4}{*}{$\begin{array}{l}\text { Total white } \\
\text { blood cell }\end{array}$} & 30 & $15.65 \pm 0.55$ & $11.46 \pm 1.10$ & $13.10 \pm 0.96$ & $12.28 \pm 1.77$ \\
\hline & 60 & $10.70 \pm 1.43$ & $13.59 \pm 2.56$ & $10.51 \pm 2.17$ & $9.78 \pm 1.35$ \\
\hline & 90 & $12.01 \pm 0.77$ & $15.24 \pm 1.47$ & $12.69 \pm 0.84$ & $16.29 \pm 3.36$ \\
\hline & 30 & $3.87 \pm 0.61$ & $3.42 \pm 0.87$ & $4.12 \pm 0.48$ & $3.32 \pm 0.75$ \\
\hline \multirow[t]{3}{*}{ Neutrophil } & 60 & $2.46 \pm 0.31$ & $2.19 \pm 0.35$ & $2.10 \pm 0.42$ & $1.90 \pm 0.30$ \\
\hline & 90 & $1.95 \pm 0.30$ & $2.34 \pm 0.82$ & $2.04 \pm 0.33$ & $2.24 \pm 0.22$ \\
\hline & 30 & $11.00 \pm 0.76$ & $7.31 \pm 1.49$ & $8.46 \pm 1.08$ & $8.32 \pm 1.89$ \\
\hline \multirow[t]{3}{*}{ Lymphocyte } & 60 & $7.80 \pm 1.11$ & $10.99 \pm 2.40$ & $8.23 \pm 1.72$ & $7.62 \pm 1.21$ \\
\hline & 90 & $9.54 \pm 0.84$ & $12.38 \pm 1.50$ & $10.11 \pm 0.69$ & $10.26 \pm 1.46$ \\
\hline & 30 & $0.19 \pm 0.03$ & $0.33 \pm 0.10$ & $0.35 \pm 0.15$ & $0.58 \pm 0.13^{*}$ \\
\hline \multirow[t]{3}{*}{ Eosinophil } & 60 & $0.32 \pm 0.06$ & $0.18 \pm 0.09$ & $0.12 \pm 0.08^{*}$ & $0.14 \pm 0.02^{*}$ \\
\hline & 90 & $039 \pm 0.02$ & $0.44 \pm 0.04$ & $0.54 \pm 0.10$ & $0.58 \pm 0.30$ \\
\hline & 30 & $0.47 \pm 0.07$ & $0.32 \pm 0.11$ & $0.13 \pm 0.05$ & $0.05 \pm 0.05$ \\
\hline \multirow[t]{3}{*}{ Monocyte } & 60 & $0.03 \pm 0.03$ & $0.23 \pm 0.10$ & $0.13 \pm 0.08$ & $0.12 \pm 0.06$ \\
\hline & 90 & $0.08 \pm 0.08$ & $0.04 \pm 0.04$ & 0 & $0.07 \pm 0.07$ \\
\hline & 30 & $0.04 \pm 0.04$ & $0.07 \pm 0.04$ & $0.04 \pm 0.04$ & 0 \\
\hline \multirow[t]{2}{*}{ Basophil } & 60 & $0.09 \pm 0.03$ & 0 & $0.04 \pm 0.04$ & 0 \\
\hline & 90 & $0.06 \pm 0.03$ & $0.04 \pm 0.04$ & 0 & 0 \\
\hline
\end{tabular}

Table 1 

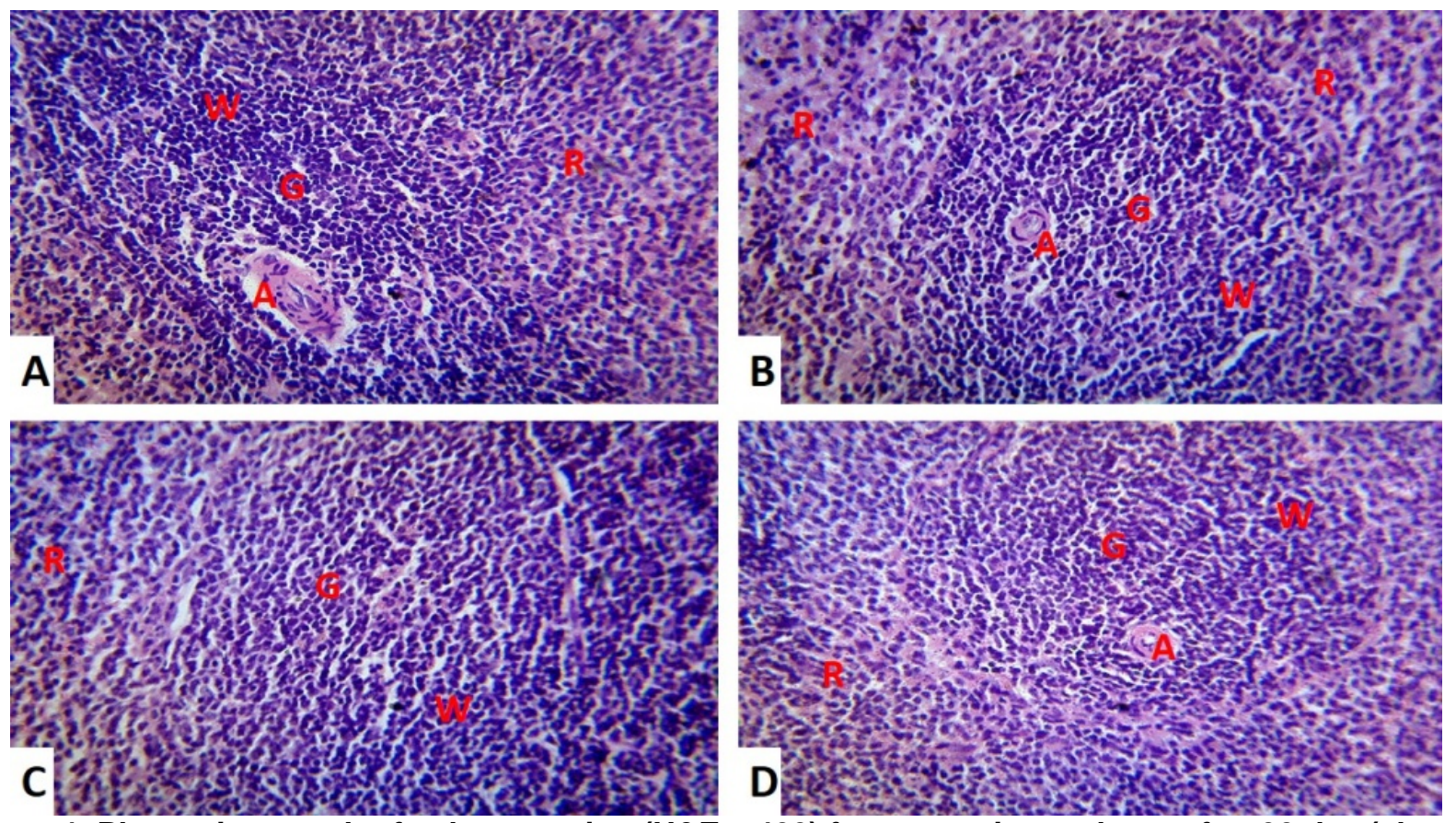

Figure 1. Photomicrograph of spleen section (H\&E, $x 400)$ from experimental rats after 90 day (chronic study) treatment with HLEHA incorporated in feed.

The ' $G$ ' indicates the germinal center, 'W' shows white pulp; ' $R$ ' shows red pulp, ' $A$ ' shows the central artery and ' $T$ ' shows the trabeculae. $A=$ control group; $B=$ HLEHA $2.50 \mathrm{mg} / 10 \mathrm{~g}$ feed group; $\mathrm{C}$ $=$ HLEHA $5.00 \mathrm{mg} / 10 \mathrm{~g}$ feed group; $\mathrm{D}=$ HLEHA $10.00 \mathrm{~g} / 10 \mathrm{~g}$ feed group.

This study was designed to evaluate the effects of the hydromethanol extract of $H$. annuus on leucocyte profile and spleen histology after prolonged exposure to rats. The natives use decoction of $H$. annuus in the treatment of chronic diseases like diabetes mellitus and there is every reason to use it for long period of time [20]. The extract was incorporated in feed to avoid the stress of daily handling and dosing that would be the norm if oral administration via stomach gavage were adopted. The degree of incorporation of the extract in the feed was based on the report of previous studies [6, 21]. The essence is to assess the impact of prolonged use of the extract in the body defense (immune) system of the rats; with a view of extrapolating the effect in humans when used for a long time.

The total and differential leucocyte count of the rats treated with HLEHA for 90 days were determined to assess the effects on leucocyte profile. The HLEHA treatment did not cause a significant $(p>0.05)$ effect on the leucocytic profile (except eosinophil) when compared with the control. The leucocytic profile of rodent is influenced by site of blood collection, age, gender, anaesthesia, method of restraint, temperature and stress [22]. Here, we used only female rats to avoid variation that may occur due to sex difference which is linked to hormonal effects [22]. Das and Mohanty [23], reported higher leucocyte count in female than in the male and attributed it to sexual dimorphism. Elevated leucocyte count indicates boost in immune response while a decrease in leucocyte count denotes suppression of immune response [23]. Deficiency of lipotrope (Choline, methionine and Vitamin $\mathrm{B}_{12}$ ) alters leucocyte count. In suckling dams and juveniles, lipotrope deficiency is associated with reduced immune response via depletion in $\mathrm{T}$ lymphocyte and increase the susceptibility of the animal to infection [14]. Blood samples collected via cardiocentesis have reduced hemoglobin concentration, packed cell volume, leucocyte and erythrocyte count when compared with blood samples collected through either from tail vein or retro-orbital plexus. Circadian rhythm and stress affects the leucocyte count. The leucocyte count is higher in the day time than the night hours, while stress produce increase in lymphocyte concentration and decrease in neutrophil concentration [22]. Poisonous chemical like benzo( $\alpha$ )pyrene and dichlorvus elicit increase in leucocyte concentration $[24,25]$. In rats, the lymphocyte and neutrophil represent $60-75 \%$ and $12-38 \%$ of leucocyte count respectively, while eosinophil, basophil and monocyte levels vary within $0-7 \%$ of leucocyte count $[22,26]$. In this study, the leucocytic profiles of the rats were within the established reference interval. The neutrophil count decreased while the lymphocyte 
count increased with the aging of the rat. This is in contrast with the information contained in Campbell [22]; neutrophil level increases while the lymphocyte level decreases with age. This finding may be attributed to the feed, strain of the animal used and environmental factor [27, 28]. The report of Campbell [22] was in reference to rats in the temperate region while our work was done in the tropics. There was no significant $(p<0.05)$ difference in the neutrophil-lymphocyte ratio, both among the group and across the period. This indicates that the extract treatment did not cause stress in the treated animal and had no significant effect on the leucocytic profile [29].

The decrease in eosinophil level in the extract treated groups could be attributed to the reported anti-inflammatory properties of methanol extract of $H$. annuus [31]. Anti-inflammatory agents such as corticosteroids reduce the level of circulating eosinophil. The circulating eosinophils are increased in response to allergy. Allergen stimulates the release of histamine from the basophils, which further initiate the release of other inflammatory cytokines [31]. Allergic reaction is treated with antihistamine and antiinflammatory agent. The extract is used in folklore medicine as an expectorant, which suggests that it may have an $\mathrm{H}_{1}$ receptor antagonist.

The spleen is a dark red to blue-black organ located in the left upper abdomen beneath the diaphragm. It is within the omentum and close to the greater curvature of the stomach [32, 33]. It has 2 distinct functional and morphological parts, the red pulp and the white pulp. The red pulp removes foreign material and damaged and wornout erythrocytes from the circulation. It is the storage portal for iron, erythrocytes, and platelets, and site of hematopoiesis in fetal and neonatal animals [34]. The spleen, white pulp, is a lymphoid organ involved in the production of lymphocytes and initiates immune responses to blood-borne antigens [32]. The spleen also acts as a communication center for different immune cells ( $T$ cells, B cells, macrophages/monocytes, and dendritic cells) to associate with each other, in order to initiate adaptive immune responses [35]. The cell population in the spleen is influenced by diet. Diet deficient in choline causes depletion of B- cells population in spleen [14]. In this study, different concentrations of the extract did not cause significant histological changes in the spleen architecture when compared with the normal group of rats. This finding was corroborated with the lymphocyte count in the various groups of rats exposed to the extract, which suggests that the extract did not impact negatively on the lymphocyte production and immune response of the rats. This may be responsible for the prolonged use of the extract by the natives in the management of diabetes mellitus without any deleterious effect.

\section{Conclusions}

The prolonged administration of low doses of hydromethanol extract of $H$. annuus does not impact negatively on the leucocyte profile and the histology of spleen.

\section{Acknowledgements}

We acknowledge the contribution of $\mathrm{Mr} \mathrm{A}$. O. Ozioko for the identification of the plant sample.

\section{Conflict of interest statement}

We declare that we have no conflict of interest

\section{References}

1. Kaid, F., Alabsi, A.M., Alafifi, N., Ali-Saeed, R., Ameen, A.M., Ramanathan, A. \& Ali, A.M. (2019). Histological, biochemical, and hematological effects of Goniothalamin on selective internal organs of male Sprague-Dawley rats. Journal of Toxicology. https://doi.org/10.1155/2019/6493286

2. World Health Organization (2000). General guidelines for methodologies on research and evaluation of traditional medicine. World Health Organization. Retrieved July, 20, 2020, from https://apps.who.int/iris/bitstream/handle/10665/66783/ WHO EDM TRM 2000.1.pdf

3. World Health Organization. (2002). Traditional medicine strategy 2002-2005. Geneva: World Health Organization.

4. Habtom, G.K. (2018). Perceptions and attitudes of modern and traditional medical practitioners about traditional medical practice in Eritrea. International Journal of Complementary and Alternative Medicine, 11 (1), 6-19. DOI: 10.15406/ijcam.2018.11.00340

5. Sen, S. \& Chakraborty, R. (2017). Revival, modernization and integration of Indian traditional herbal medicine in clinical practice: Importance, challenges and future. Journal of Traditional and Complementary Medicine, 7 (2), 234-44. DOI: 10.1016/j.jtcme.2016.05.006

6. Onoja, S.O., Udem, S.C., Anaga, A.O. \& Asuzu, I.U. (2018). Acute and chronic toxicity studies of hydromethanol leaf extract of Helianthus annuus Linn. in rats. Asian Pacific Journal of Tropical Medicine, 11(9), 534-539. https://www.apjtm.org/text.asp?2018/11/9/534/242311 7. Mensah, M.L., Komlaga, G., Forkuo, A.D., Firempong, C., Anning, A.K. \& Dickson, R.A. (2019). Toxicity and safety implications of herbal medicines used in Africa, Herbal Medicine, Philip F. Builders, IntechOpen.

8. Debelo, N., Afework, M., Debella, A., Makonnen, E., Ergete, W. \& Geleta, B. (2016). Assessment of hematological, biochemical and histopathological effects of acute and sub-chronic administration of the aqueous leaves extract of Thymus schimperi in rats. Journal of Clinical Toxicology, 6 (286), 2161-0495.

9. Kale, O.E., Awodele, O. \& Akindele, A.J. (2019). Subacute and subchronic oral toxicity assessments of 
Acridocarpus smeathmannii (DC.) Guill. \& Perr. root in Wistar rats. Toxicology Reports, 6, 161-75.

10. Olayode, O.A., Daniyan, M.O. \& Olayiwola, G. (2019). Biochemical, hematological and histopathological evaluation of the toxicity potential of the leaf extract of Stachytarpheta cayennensis in rats. Journal of Traditional and Complementary Medicine, https://doi.org/10.1016/j.jtcme.2019.05.001

11. Banerjee, B.D. (1999). The influence of various factors on immune toxicity assessment of pesticide chemicals. Toxicology Letters, 107 (1-3), 21-31.

12. Gessner, D.K., Ringseis, R. \& Eder, K. (2017). Potential of plant polyphenols to combat oxidative stress and inflammatory processes in farm animals. Journal of Animal Physiology and Animal Nutrition, 101 (4), 605-628.

13. Hopkins, A., Rowland, A., Kichenadasse, G., Wiese, M.D., Gurney, H., McKinnon, R.A., Karapetis, C.S. \& Sorich, M.J. (2017). Predicting response and toxicity to immune checkpoint inhibitors using routinely available blood and clinical markers. British Journal of Cancer, 117, 913-920. doi: 10.1038/bjc.2017.274

14. Lewis, E.D., Goruk, S., Richard, C., Dellschaft, N.S., Curtis, J.M., Jacobs, R.L. \& Field, C.J. (2016). Feeding a diet devoid of choline to lactating rodents restricts growth and lymphocyte development in offspring. Bristish Journal of Nutrition, 116 (6), 10011012. DOI: $10.1017 /$ S0007114516002919

15. Onoja, S.O., Udem, S.C. \& Anaga, A.O. (2017). Effect of chronic administration of hydromethanol leaf extract of Helianthus annuus on erythrocytic profile in normal rats. Journal of Nutritional Therapy, 6 (2), 5963.

16. Ejebe, D.E., Emudainohwo, J.O., Akonoghrere, R., Olise, C.C., Amadi, C.N. \& Siminialayi, I.M. (2008). Effects of ethanol extract of leaves of Helianthus annuus on the reproductive system of male wistar rats: Testicular histology, epididymal sperm properties and blood levels of reproductive hormones. Biomedical and Pharmacology Journal, 1 (1), 65-78.

17. Onoja, S.O. \& Anaga, A.O. (2014). Evaluation of the antidiabetic and antioxidant potentials of methanolic leaf extract of Helianthus annuus L. on alloxan-induced hyperglycemic rats. Comparative Clinical Pathology, 23, 1565-1573.

18. Brar, R.S., Sandhu, H.S. \& Singh, A. (2000). Veterinary clinical diagnosis by laboratory methods. New Delhi: Kalyani Publishers.

19. Ezeja, M.I., Anaga, A.O. \& Asuzu, I.U. (2014). Acute and sub-chronic toxicity profile of methanol leaf extract of Gouania longipetala in rats. Journal of Ethnopharmacology, 151 (3), 1155-1164

20. Craig, M.E., Jefferies, C., Dabelea, D., Balde, N., Seth, A. \& Donaghue, K.C. (2014) Definition, epidemiology, and classification of diabetes in children and adolescents. Pediatrics Diabetes, 15(Suppl 20), 417.

21. Ferreira, I.C.F.R., Martins, N. \& Barros, L. (2017). Phenolic compounds and its bioavailability: In vitro bioactive compounds or health promoters? Advances in Food and Nutrition Research, 82, 1-44.

22. Campbell, T.W. (2012) Mammalian Hematology: Laboratory Animals and Miscellaneous Species. In:
Thrall MA, Weiser G, Allison RW, Campbell TW (eds) Veterinary hematology and clinical chemistry, 2nd edn. Wiley-Blackwell, Hoboken, pp 225-237.

23. Das, A. \& Mohanty, P.K. (2018). Comparative hemocytobiochemical profile of Rattus rattus Linnaeus, 1758 and Rattus norvegicus Berkenhout, 1769. Comparative Clinical Pathology, 27, 1509-1514.

24. Ajao, M.S., Sansa, A.B., Imam, A., Ibrahim, A., Adana, M.Y., Alli-Oluwafuyi, A. \& Kareem, S.B. (2017). Protective Effect of Nigella Sativa (Black Caraway (Oil on Oral Dichlorvos Induced Hematological, Renal and Nonspecific Immune System Toxicity in Wistar Rats. Iranian Journal of Toxicology, $11(6), 1-5$.

25. Widiastuti, E.L., Arifianti, R., Khairani, I.A., Christianto, Y., Ara, N.F. \& Maharani. H.W. (2019). Antioxidant Effect of Clerodendrum sp and Acanthus illicifolius Methanol Extraction on Blood Profile of Male Mice Induced by Benzo (a) pyrene. IOP Conference Series: Earth and Environmental Science, 305, 012011. doi:10.1088/1755-1315/305/1/012011

26. Akpovona, A. \& Onoagbe, I. (2018). Investigation of haematological effects of Terminalia macroptera stem bark via platelet-to-lymphocyte ratio among other blood parameters in Wistar rats. Biokemistri, 30 (1), 3241.

27. Drummond, G.B. (2009). Reporting ethical matters in The Journal of Physiology: standards and advice. Journal of Physiology, 587 (4), 713-719.

28. Richter, F., Fehske, A.J. \& Fettweis, G.P. (2009) Energy efficiency aspects of base station deployment strategies for cellular networks. In Vehicular Technology Conference Fall (VTC 2009-Fall), IEEE 70th (pp. 1-5). IEEE.

29. Davis, A.K., Maney, D.L. \& Maerz, J.C. (2008). The use of leukocyte profiles to measure stress in vertebrates: a review for ecologists. Functional Ecology, 22 (5), 760-772.

30. Emamuzo, E.D., Miniakiri, S.I., Tedwin, E.J., Ufouma, O. \& Lucky, M. (2010). Analgesic and antiinflammatory activities of the ethanol extract of the leaves of Helianthus Annus in Wistar rats. Asian Pacific Journal of Tropical Medicine, 3 (5), 341-347.

31. He, S.H., Zhang, H.Y., Zeng, X.N., Chen, D. \& Yang, P.C. (2013). Mast cells and basophils are essential for allergies: mechanisms of allergic inflammation and a proposed procedure for diagnosis. Acta Pharmacologica Sinica, 34 (10): 1270-1283.

32. Cesta, M.F. (2006). Normal structure, function, and histology of the spleen. Toxicologic Pathology, 34 (5), 455-465.

33. Mebius, R.E. \& Kraal, G. (2005). Structure and function of the spleen. Nature Reviews Immunology, 5 (8), 606-616.

34. Lewis, S.M., Williams, A. \& Eisenbarth, S.C. (2019). Structure and function of the immune system in the spleen. Science Immunology, 4 (33), eaau6085. doi: 10.1126/sciimmunol.aau6085.

35. Seifert, H.A. \& Offner, H. (2018). The splenic response to stroke: from rodents to stroke subjects. Journal of Neuroinflammation, 15 (1), 195. https://doi.org/10.1186/s12974-018-1239-9 